Quality : Jurnal Kesehatan

Volume 15, Nomor 1 Tahun 2021

pISSN : 1978-4325, eISSN : 2655-2434, DOI: 10.36082/qjk.v15i1.124

\title{
HUBUNGAN KUALITAS LAYANAN PRAKTEK KLINIK DENGAN KEPUASAN MAHASISWA JURUSAN KEPERAWATAN GIGI
}

\author{
Ni Nyoman Kasihani ${ }^{1}$, Rini Widyastuti ${ }^{2}$, Indrayati Fadjeri ${ }^{3}$, Emini $^{4}$ \\ 1,2,3,4 Jurusan Keperawatan Gigi, Politeknik Kesehatan Kemenkes Jakarta I, Indonesia
}

\begin{abstract}
Info Artikel Abstrak
Genesis Naskah:

Latar belakang: Mahasiswa adalah salah satu pelanggan dalam dunia pendidikan. Kepuasan

Submitted: 14-07-2020

Revised: 19-05-2021

terhadap kualitas layanan penting dilakukan evaluasi secara berkala untuk perbaikan kinerja, agar sesuai dengan yang diharapkan mahasiswa. Tujuan: untuk menganalisis hubungan kualitas layanan praktek klinik terhadap kepuasan mahasiswa di Jurusan Keperawatan Gigi Poltekkes

Accepted: 27-05-2021 Kemenkes Jakarta I. Metode: Jenis penelitian observasional dengan rancangan cross sectional, dilakukan pada bulan Juni-Oktober 2018. Penelitian tentang lima dimensi kepuasan layanan praktek klinik dilakukan pada seluruh mahasiswa tingkat 2 dan 3. Penelitian dilakukan dengan total sampling. Instrument penelitian menggunakan kuesioner dengan hasil uji validitas Korelasi Product Moment antara 0,222 - 0,668 dan uji reliabilitas Koefisien Alpha Cronbach 0,710. Analisis data

Kata Kunci:

Kualitas praktek klinik, kepuasan, mahasiswa

dengan uji univariate, Chi-Square dan Regresi Logistik Multivariabel. Hasil: Sebagian besar mahasiswa merasa puas terhadap layanan praktek klinik dengan persentase $60,5 \%$. Variabel dimensi kualitas layanan klinik yaitu bukti langsung, kehandalan, daya tanggap, jaminan dan empati memiliki hubungan yang signifikan dengan kepuasan mahasiswa dengan nilai $\mathrm{p}$ value < 0,05 . Dimensi jaminan memiliki hubungan yang paling besar dengan kepuasan mahasiswa dengan nilai OR 482,497. Kesimpulan: Sebagian besar mahasiswa merasa puas terhadap layanan klinik. Dimensi kualitas layanan klinik memiliki hubungan yang signifikan dengan kepuasan mahasiswa. Variabel Jaminan memiliki hubungan terbesar dengan kepuasan mahasiswa.
\end{abstract}

\section{RELATIONSHIP QUALITY CLINICAL PRACTICE SERVICES WITH THE SATISFACTION OF STUDENTS OF DENTAL NURSING}

Keywords:
Quality of clinical practice,
satisfaction, student

satisfaction, student

\begin{abstract}
Background: Students are one of the customers in the world of education. Satisfaction with the quality of service is important to be evaluated regularly to improve performance, so that it is in line with what students expect. Aim: to analyze the relationship between clinical practice service quality and student satisfaction in the Dental Nursing Department of the Ministry of Health, Jakarta I. Method: This type of observational study with a cross sectional design, was conducted in JuneOctober 2018. Research on five dimensions of clinical practice service satisfaction was conducted on all students level 2 and 3. Research conducted with total sampling. The research instrument used a questionnaire with the results of the Product Moment Correlation test validity between $0.222-0.668$ and the reliability test of the Alpha Cronbach coefficient of 0.710. Data analysis with univariate test, ChiSquare and Multivariable Logistic Regression. Results: Most of the students were satisfied with clinical practice services with a percentage of $60.5 \%$. The dimensions of clinical service quality dimensions, tangibles, reliability, responsiveness, assurance and empathy have a significant relationship with student satisfaction with a $p$ value <0.05. The assurance dimension has the greatest relationship with student satisfaction with an OR value of 482,497. Conclusion: Most
\end{abstract}

(C) Poltekkes Kemenkes Jakarta I

Jl. Wijaya Kusuma No. 47-48 Cilandak Jakarta Selatan, Indonesia

email: jurnalquality@poltekkesjakarta1.ac.id 
students were satisfied with clinical services. The dimensions of clinical service quality have a significant relationship with student satisfaction. The assurance variable has the greatest relationship with student satisfaction.

Korespondensi Penulis:

Ni Nyoman Kasihani

Jl. Wijayakusuma Raya, No. 47. Cilandak, Jakarta Selatan Indonesia

Email: Nyoman.kasihani@gmail.com

(C) Poltekkes Kemenkes Jakarta I

Jl. Wijaya Kusuma No. 47-48 Cilandak Jakarta Selatan, Indonesia email: jurnalquality@poltekkesjakarta1.ac.id 


\section{Pendahuluan}

Jurusan Keperawatan Gigi merupakan salah satu pendidikan tinggi vokasi yang menghasilkan tenaga kesehatan. Menjaga kualitas pelayanan kepada mahasiswa merupakan bagian dari sistem penjaminan mutu agar pendidikan yang diselenggarakan sesuai dengan standar yang ditetapkan.

Persaingan antar perguruan tinggi semakin ketat. Perguruan tinggi harus memberikan layanan yang maksimal kepada mahasiswa sebagai konsumen. Kepuasan mahasiswa merupakan tujuan utama dari setiap perguruan tinggi. Hasil penelitian yang dilakukan di FMIPA Universitas Negeri Padang menunjukkan bahwa indeks kepuasan mahasiswa terhadap layanan akademik mencapai skor 68,82 dan termasuk kategori kurang puas (Amalita et al., 2021).

Keluhan mahasiswa terkait layanan pendidikan harus segera ditindaklanjuti, agar kualitas layanan sesuai dengan yang diharapkan. Bila diabaikan, dampak yang dapat timbul adalah penurunan peminat, lulusan yang tidak sesuai standar dan tidak terserap di dunia kerja. Pendidikan vokasi memiliki kurikulum dengan kegiatan praktik lebih banyak dibandingkan teori. Kompetensi keterampilan klinik mahasiswa harus sesuai dengan persyaratan dalam kurikulum. Evaluasi kepuasan mahasiswa terhadap layanan praktik yang diselenggarakan perlu dilakukan evaluasi secara berkala, agar segera dapat dilakukan perbaikan dan lulusan memiliki keahlian sesuai dengan kompetensi yang ditentukan.

Lima dimensi kepuasan layanan menurut Parasuraman (Lupiyoadi, Rambat, 2006) terdiri atas bukti langsung (tangibles), kehandalan (reliability), daya tanggap (responsiveness), jaminan (assurance) dan empati (emphaty). Mahasiswa dalam proses penyelesaian pendidikan harus menyelesaikan berbagai penugasan baik teori, praktek di laboratorium/ klinik/lapangan. Tujuan dari penelitian ini adalah untuk melakukan analisis kualitas layanan praktik klinik terhadap kepuasan mahasiswa yang diselenggarakan di Jurusan Keperawatan Gigi Poltekkes Kemenkes Jakarta I.

\section{Metode}

Jenis penelitian observasional dengan rancangan cross sectional, dilakukan pada bulan Juni-Oktober 2018 di Jurusan Keperawatan Gigi Poltekkes Kemenkes Jakarta I. Penelitian dilakukan pada seluruh mahasiswa tingkat 2 dan 3 yang sudah melakukan praktik klinik. Pengambilan sampel dilakukan secara total sampling karena jumlah populasi tidak terlalu besar sebanyak 157 responden Variabel penelitian yang diteliti adalah bukti langsung (tangibles), kehandalan (reliability), daya tanggap (responsiveness), jaminan (assurance) dan empati (emphaty). Instrumen penelitian menggunakan kuesioner dengan 17 butir pernyataan Skala Likert (Azwar, 2011). Kuesioner berisi pernyataan tentang sarana dan prasarana, kompetensi dosen, pranata laboratorium dan teknisi, kecepatan layanan, jaminan layanan dan empati. Hasil uji validitas Korelasi Product Moment terdapat 1 pernyataan tidak valid dengan hasil antara $0,222-$ 0,668 dan uji reliabilitas Koefisien Alpha Cronbach 0,710. Kuesioner dinyatakan semakin reliabel apabila hasil uji semakin mendekati angka 1 (Azwar, 2012). Analisis data dengan uji univariate, ChiSquare untuk mengetahui ada tidaknya hubungan antara dimensi kualitas layanan dengan kepuasan mahasiswa dan Regresi Logistik Multivariabel untuk mengetahui variabel dimensi kualitas layanan mana yang memiliki pengaruh paling besar terhadap kepuasan mahasiswa.

\section{Hasil}

Berdasarkan hasil penelitian, karakteristik responden yang dibedakan atas usia dan jenis kelamin diperoleh data sebagai berikut.

Tabel 1. Karakteristik responden

\begin{tabular}{|l|c|c|}
\hline Karakteristik & Jumlah & $\%$ \\
\hline Usia & & \\
$\leq 25$ tahun & 84 & 54 \\
$>25$ tahun & 73 & 46 \\
\hline Jenis Kelamin & & \\
Laki-laki & 137 & 87 \\
Perempuan & 20 & 13 \\
\hline
\end{tabular}

(C) Poltekkes Kemenkes Jakarta I

Jl. Wijaya Kusuma No. 47-48 Cilandak Jakarta Selatan, Indonesia email: jurnalquality@poltekkesjakarta1.ac.id

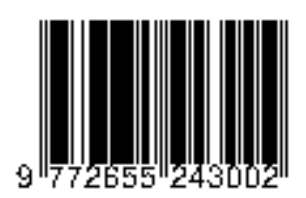


Responden penelitian terdiri atas mahasiswa reguler umum dan reguler karyawan. Sebagian besar mahasiswa yang berusia $\leq 25$ tahun sebesar $54 \%$ merupakan mahasiswa reguler umum. Jenis kelamin mahasiswa sebesar $84 \%$ adalah perempuan.

Kepuasan mahasiswa diukur untuk mengetahui kualitas layanan klinik yang selama ini dilaksanakan di Jurusan Keperawatan Gigi. Berdasarkan hasil pengukuran kepuasan mahasiswa didapatkan data sesuai dengan gambar di bawah ini.

Tingkat Kepuasan Mahasiswa Terhadap Kualitas Layanan Praktik Klinik

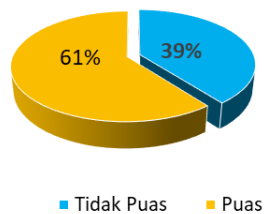

Gambar 1. Tingkat kepuasan mahasiswa terhadap layanan praktik klinik

Berdasarkan Gambar 1 diketahui bahwa $61 \%$ mahasiswa merasa puas terhadap layanan praktik klinik dan sebesar 39\% mahasiswa merasa tidak puas.

Analisis untuk mengetahui ada tidaknya hubungan antara 5 dimensi kualitas layanan terhadap kepuasan mahasiswa dilakukan uji Chi-Square dengan hasil sebagai berikut.

(C) Poltekkes Kemenkes Jakarta I

Jl. Wijaya Kusuma No. 47-48 Cilandak Jakarta Selatan, Indonesia email: jurnalquality@poltekkesjakarta1.ac.id
Tabel 2. Hasil analisis Chi-Square dimensi kualitas layanan dengan kepuasan mahasiswa

\begin{tabular}{|c|c|c|c|c|c|c|c|c|}
\hline \multirow{3}{*}{$\begin{array}{l}\text { Dimensi } \\
\text { kualitas } \\
\text { layanan }\end{array}$} & \multicolumn{4}{|c|}{ Tingkat kepuasan } & \multirow{2}{*}{\multicolumn{2}{|c|}{ Total }} & \multirow{3}{*}{$\begin{array}{c}\text { OR } \\
(95 \% \\
\text { CI })\end{array}$} & \multirow{3}{*}{ p value } \\
\hline & \multicolumn{2}{|c|}{ Tidak puas } & \multicolumn{2}{|c|}{ Puas } & & & & \\
\hline & $\mathrm{N}$ & $\%$ & $\mathrm{~N}$ & $\%$ & $\mathrm{~N}$ & $\%$ & & \\
\hline \multicolumn{9}{|c|}{ Bukti Langsung (tangibels), } \\
\hline Kurang baik & 29 & 50 & 29 & 50 & 58 & 100 & 2 & \multirow{3}{*}{0,058} \\
\hline Baik & 33 & 33,3 & 66 & 66,7 & 99 & 100 & $1,0-3,8$ & \\
\hline Jumlah & 62 & 39,5 & 95 & 60,5 & 157 & 100 & & \\
\hline \multicolumn{9}{|c|}{ Kehandalan (reliability) } \\
\hline Kurang baik & 42 & 84 & 8 & 16 & 50 & 100 & 22,838 & \multirow{3}{*}{0,000} \\
\hline Baik & 20 & 18,7 & 87 & 81,3 & 107 & 100 & & \\
\hline Jumlah & 62 & 39,5 & 95 & 60,5 & 157 & 100 & $\begin{array}{l}9,2- \\
56,1\end{array}$ & \\
\hline \multicolumn{9}{|c|}{ Daya Tanggap (responsiveness) } \\
\hline Kurang Baik & 38 & 88,4 & 5 & 11,6 & 43 & 100 & 28,5 & \multirow{3}{*}{0,000} \\
\hline Baik & 24 & 21,1 & 90 & 78,9 & 114 & 100 & & \\
\hline Jumlah & 62 & 39,5 & 95 & 60,5 & 157 & 100 & $\begin{array}{l}101- \\
80.2\end{array}$ & \\
\hline \multicolumn{9}{|c|}{ Jaminan (assurance) } \\
\hline Kurang Baik & 43 & 95,6 & 2 & 4,4 & 45 & 100 & 105,237 & \multirow{3}{*}{0,000} \\
\hline Baik & 19 & 17 & 93 & 83 & 112 & 100 & & \\
\hline Jumlah & 62 & 39,5 & 95 & 60,5 & 157 & 100 & $\begin{array}{l}23,4- \\
4271\end{array}$ & \\
\hline \multicolumn{9}{|c|}{ Empati (emphaty) } \\
\hline Kurang Baik & 19 & 95 & 1 & 5 & 20 & 100 & 41,535 & \multirow{3}{*}{0,000} \\
\hline Baik & 43 & 31,4 & 94 & 68,6 & 137 & 100 & & \\
\hline Jumlah & 62 & 39,5 & 95 & 60,5 & 157 & 100 & $\begin{array}{r}5,3- \\
320,3\end{array}$ & \\
\hline
\end{tabular}

Berdasarkan hasil analisis Chi-Square pada Tabel 2 bahwa seluruh komponen dalam dimensi kualitas layanan klinik yaitu bukti langsung, kehandalan, daya tanggap, jaminan dan empati memiliki hasil $\mathrm{p}$ value $<0,05$, sehingga kelima dimensi tersebut memiliki hubungan yang signifikan dengan kepuasan mahasiswa.

Setelah dilakukan analisis bivariat dengan Chi Square, maka selanjutnya data dianalisis dengan Regresi Logistik Multivariabel untuk menganalisis variabel bebas secara bersama-sama untuk mengetahui variabel yang hubungannya paling dominan antara dimensi kualitas layanan klinik terhadap kepuasan mahasiswa (Hastono, 2017). Hasil seleksi kandidat bivariat diperoleh hasil:

Tabel 3. Hasil seleksi kandidat bivariate

\begin{tabular}{|c|c|c|}
\hline No & Komponen & $\begin{array}{c}p \\
\text { values }\end{array}$ \\
\hline 1 & Bukti langsung (tangibles) & 0,058 \\
\hline 2 & Kehandalan (reliability) & 0,000 \\
\hline 3 & $\begin{array}{l}\text { Daya } \\
\text { (responsiveness) }\end{array}$ & 0,000 \\
\hline 4 & Jaminan (assurance) & 0,000 \\
\hline 5 & Empati (emphaty) & 0,000 \\
\hline \multicolumn{3}{|c|}{ ISSN 2655-2434 } \\
\hline
\end{tabular}


Berdasarkan Tabel 3, terdapat 5 variabel yang masuk ke seleksi regresi logistik yaitu seluruh variabel dimensi kualitas layanan

\section{Pemodelan Analisis Multivariabel}

Pada tahap Regresi Logistik multivariabel, semua variabel yang sudah lolos tahap seleksi bivariate dilakukan analisis secara bersama-sama dalam model. Hasil pemodelan sebagai berikut :

Tabel 4. Pemodelan Regresi Logistik Multivariabel

\begin{tabular}{|l|c|c|c|c|}
\hline \multicolumn{1}{|c|}{ Variabel } & $\mathrm{B}$ & $\mathrm{p}$ value & OR & $95 \%$ CI \\
\hline Bukti langsung (tangibles) & 5,017 & 0,001 & 150,905 & $\begin{array}{c}6,906- \\
3297,663\end{array}$ \\
\hline Kehandalan (reliability) & 5,589 & 0 & 267,43 & $\begin{array}{c}17,832- \\
4010,677\end{array}$ \\
\hline $\begin{array}{l}\text { Daya tanggap } \\
\text { (responsiveness) }\end{array}$ & 5,478 & 0,001 & 239,274 & $\begin{array}{c}9,875- \\
5797,554\end{array}$ \\
\hline Jaminan (assurance) & 6,179 & 0 & 482,479 & $\begin{array}{c}15,099- \\
15417,058\end{array}$ \\
\hline Empati(emphaty) & 5,906 & 0,015 & 367,384 & $\begin{array}{c}3,089- \\
43698,525\end{array}$ \\
\hline
\end{tabular}

Berdasarkan tabel 4, dari 5 variabel dimensi layanan klinik, variabel yang memiliki hubungan terbesar dengan kepuasan mahasiswa dilihat dari variabel yang memiliki nilai OR terbesar yaitu variabel jaminan dengan nilai OR 482,479 dengan nilai $95 \%$ CI sebesar 15,099-15417,058 dan nilai $\mathrm{p}$ value 0 . Variabel dimensi kualitas layanan berikutnya yang secara berturut-turut memiliki pengaruh terhadap kepuasan mahasiswa adalah empati dengan nilai OR 367,384 (CI 95\% 3,08943698,525), kehandalan dengan nilai OR 267,43 (CI 95\% 17,832-4010,677), daya tanggap dengan nilai OR 239,274 (95\% CI 9,875-5797,554) dan terakhir adalah bukti langsung dengan nilai OR 150,905 (95\% CI 6,906-3297,663). Seluruh dimensi memiliki nilai $p$ value $<0,05$. Bukti langsung terkait sarana dan prasarana memiliki pengaruh terendah terhadap kepuasan kualitas layanan, namun terdapat satu pernyataan dalam kuesioner yang memiliki nilai kurang baik yaitu dental unit $(67,5 \%$ mahasiswa menyatakan kurang baik). Selain itu, semua sarana dan prasarana peralatan pemeriksaan, fasilitas ruang tunggu, kebersihan dan kenyamanan memiliki nilai baik.

(C) Poltekkes Kemenkes Jakarta I

Jl. Wijaya Kusuma No. 47-48 Cilandak Jakarta Selatan, Indonesia email: jurnalquality@poltekkesjakarta1.ac.id

\section{Pembahasan}

Politeknik Kesehatan merupakan perguruan tinggi yang menyelenggarakan layanan jasa dibidang pendidikan kesehatan. Mahasiswa merupakan pelanggan dari sebuah institusi pendidikan. Kepuasan mahasiswa adalah salah satu hal penting yang secara berkala harus dilakukan evaluasi, sehingga perbaikan layanan dapat terus ditingkatkan sesuai dengan harapan mahasiswa dan persyaratan yang ditentukan.

Berdasarkan hasil penelitian sebagian besar mahasiswa merasa puas terhadap layanan klinik yang diselenggarakan, namun dari sisi persentase masih perlu ditingkatkan jumlahnya. Kualitas layanan praktik klinik perlu dtingkatkan, agar persentase kepuasan mahasiswa juga meningkat. Menurut (Bena, 2010) bahwa kondisi kebutuhan masyarakat selalu mengalami perubahan, baru dan kompetitif, di mana setiap institusi perlu berjuang agar tetap bertahan hidup, membuktikan bahwa membangun dan mengelola hubungan dengan pelanggan sangat penting. Dasar dari setiap hubungan jangka panjang terletak kepuasan pelanggan. Menurut (Abdullah, Mokhtar; AlNasser, Amjad D; Husain, 2000) bahwa dibutuhkan lebih dari sekedar kepuasan pelanggan untuk membuat pelanggan loyal dan membuat proses internal benar-benar responsif terhadap kebutuhan pelanggan. Hasil penelitian ini berbeda dengan hasil penelitian kepuasan mahasiswa yang dilakukan di UIN Sunan Kalijaga Yogyakarta 1, mahasiswa belum merasa puas terhadap layanan yang diterima terkait seluruh dimensi dengan urutan reliability, assurance, tangibles, responsiveness dan emphaty (Saifuddin \& Sunarsih, 2016).

Berdasarkan dimensi kualitas layanan klinik yaitu bukti langsung (tangibles), kehandalan (reliability), daya tanggap (responsiveness), jaminan (assurance) dan empati (emphaty), kelima dimensi kualitas layanan ini memiliki hubungan yang signifikan dengan kepuasan mahasiswa.

Dimensi layanan bukti langsung (tangibles) merupakan bukti fisik yang dapat dilihat oleh mahasiswa dalam penyelenggaraan layanan praktek klinik yang dilaksanakan oleh Jurusan Keperawatan Gigi. Bukti fisik yang dapat diamati adalah adanya fasilitas dental unit beserta peralatan pemeriksaan dan perawatan kesehatan gigi yang tersedia di klinik.

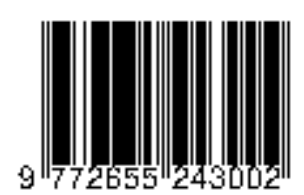


Tersedianya ruang tunggu pasien dan ruang layanan klinik yang bersih dan nyaman. Sebagian besar mahasiswa yaitu $67,5 \%$ menyatakan bahwa dental unit kondisinya kurang baik, perlu diperbaiki atau diganti. Hal ini kemungkinan disebabkan karena tingginya frekuensi pemakaian dental unit karena adanya Permenkes No. 41 tahun 2016 yang mewajibkan menerima mahasiswa RPL, sehinga jumlah mahasiswa lebih banyak dari biasanya (Kemenkes, 2016). Terkait peralatan pemeriksaan atau peralatan kerja lainnya sebagian besar mahasiswa menyatakan dalam kondisi baik, ruang tunggu dan ruang klinik bersih dan nyaman. Bukti fisik yang dilihat dan dirasakan oleh mahasiswa ini memiliki hubungan yang signifikan dengan kepuasan mahasiswa.

Dimensi layanan Kehandalan (reliability) adalah terkait kemampuan institusi untuk memberikan pelayanan sesuai yang dijanjikan secara akurat dan terpercaya. Dalam hal ini layanan klinik yang diberikan dosen sebagai pembimbing dalam praktek klinik, pranata laboratorium dalam melayani peralatan dan bahan-bahan yang diperlukan serta kehandalan tenaga teknis dalam memperbaiki fasilitas yang bermasalah. Sebagian besar mahasiswa menyatakan bahwa kemampuan dosen, pranata laboratorium dan tenaga teknis dapat diandalkan dalam memberikan layanan praktek klinik. Kehandalan (reliability) kualitas layanan klinik ini juga memiliki hubungan yang signifikan dengan kepuasan mahasiswa.

Hasil penelitian terkait dimensi layanan yaitu daya tanggap diperoleh hasil terdapat hubungan yang signifikan dengan kepuasan mahasiswa. Kecepatan daya tanggap yang diberikan dosen memiliki persentase tertinggi dibandingkan kecepatan daya tanggap yang dilakukan oleh pranata laboratorium dan petugas klinik lainnya. Hal ini sesuai dengan penelitian kinerja dosen di Kalimantan Selatan bahwa dosen memiliki nilai pribadi yang berpengaruh kuat terhadap kepuasan kerja. Kemampuan dosen untuk berpikir analitis, perilaku terstruktur, hubungan vertikal dan horizontal yang berkualitas dan mampu menyelesaikan tugas sesuai dengan ketentuan yang ada (Kuswani et al., 2015)

Dimensi layanan terkait Jaminan (assurance) adalah pengetahuan dan keterampilan,

(C) Poltekkes Kemenkes Jakarta I

Jl. Wijaya Kusuma No. 47-48 Cilandak Jakarta Selatan, Indonesia email: jurnalquality@poltekkesjakarta1.ac.id profesionalisme dan keahlian teknis dosen, pranata laboratorium dan petugas klinik dalam melakukan bimbingan dan layanan selama praktek klinik dilaksanakan. Sebagian besar mahasiswa menyatakan bahwa tingkat jaminan layanan yang diberikan baik dan dimensi ini memiliki hubungan yang signifikan dengan kepuasan mahasiswa. Variabel jaminan (assurance) memiliki hubungan terbesar dengan kepuasan mahasiswa dengan nilai OR tertinggi dibandingkan dengan variabel lainnya yaitu sebesar 48,479 yang artinya mahasiswa dengan jaminan layanan yang baik memiliki peluang 48 kali lebih puas terhadap kualitas layanan klinik yang diterima.

Dimensi layanan empati yaitu rasa peduli, respon positif dan hubungan baik antara pembimbing dan petugas klinik juga diperoleh hasil memiliki hubungan yang signifikan dengan kepuasan mahasiswa. Menurut (Gunarsa, 2000), empati merupakan salah satu cara yang efektif dalam usaha untuk mengenali, memahami dan mengevaluasi orang lain. Empati mendorong individu untuk mengubah pola pikir yang rigid menjadi fleksibel, pola pikir yang egois menjadi toleran. Variabel empati memiliki hubungan kedua terbesar setelah dimensi Jaminan (assurance) dengan kepuasan mahasiswa dengan nilai OR sebesar 367,384. Mahasiswa dengan layanan klinik yang penuh empati oleh pengelola, memiliki peluang 367 kali lebih puas terhadap layanan klinik yang diterima.

Dimensi kualitas layanan setelah variabel jaminan dan empati yang besarnya nilai OR secara berurutan memiliki pengaruh terhadap kepuasan adalah kehandalan, daya tanggap dan terakhir adalah bukti langsung. Hasil penelitian ini sebagian berbeda dengan penelitian yang dilakukan di Thailand (Polyorat, Kawpong; Sophonsiri, 2010) yang meneliti tentang pengaruh dimensi kualitas layanan terhadap kepuasan dan loyalitas pelanggan, bahwa dimensi kualitas layanan tangibles dan empati memiliki pengaruh signifikan terhadap kepuasan dan loyalitas pelanggan, sedangkan tiga dimensi lain yang tidak memiliki pengaruh signifikan yaitu reliabilitas, daya tanggap dan jaminan.

Hasil penelitian lain tentang kepuasan mahasiswa internasional dilakukan di Turki, bahwa

ISSN 2655-2434

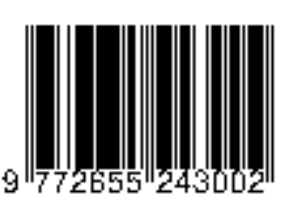


kepuasan mahasiswa merupakan faktor penting dalam mempengaruhi kualitas pembelajaran dan keberhasilan program pembelajaran. Terdapat lima faktor yang secara signifikan berpengaruh terhadap kepuasan mahasiswa yaitu persiapan diri, kualitas akademik dan pendidikan, dukungan administratif dan staf, pengaruh pribadi dan lingkungan serta keamanan (Uddin et al., 2017).

Hasil evaluasi kepuasan mahasiswa harus segera ditindaklanjuti oleh pengelola pendidikan, agar dimensi kualitas layanan yang sudah baik dapat dipertahankan atau ditingkatkan, sedangkan dimensi yang masih kurang segera diperbaiki. Tujuan dari perbaikan ini agar sesuai dengan harapan mahasiswa dan sesuai dengan standar yang ditetapkan untuk meningkatkan kualitas pembelajaran dalam rangka pencapaian kompetensi lulusan sesuai dengan persyaratan yang ditetapkan.

\section{Kesimpulan dan Saran}

Sebagian besar mahasiswa merasa puas terhadap kualitas layanan praktik klinik yang diselenggarakan. Dimensi .kualitas layanan jaminan (assurance) memiliki hubungan yang paling besar dengan kepuasan mahasiswa.

Kepuasan mahasiswa perlu ditingkatkan dengan memberikan layanan sesuai dengan harapan mahasiswa. Dimensi kualitas layanan berupa bukti fisik yaitu dental unit perlu ditingkatkan kualitasnya baik berupa pengadaan dental unit baru ataupun mempercepat proses perbaikan alat-alat yang mengalami kerusakan.

\section{Daftar Pustaka}

Abdullah, Mokhtar; Al-Nasser, Amjad D; Husain, N. (2000). Evaluating functional relationship between image, customer satisfaction and customer loyalty using general maximum entropy. Total Quality Management; Abingdon, 11(4-6), S826-S829.

Amalita, N., Fitria, D., \& Arnellis. (2021). Analysis of Student's Satisfaction to Academic Service

(C) Poltekkes Kemenkes Jakarta I

Jl. Wijaya Kusuma No. 47-48 Cilandak Jakarta Selatan, Indonesia email: jurnalquality@poltekkesjakarta1.ac.id in FMIPA Universitas Negeri Padang. Journal of Physics: Conference Series, 1742(1), 1-7. https://doi.org/10.1088/17426596/1742/1/012008

Azwar, S. (2011). Sikap Manusia; Teori dan Pengukurannya. Pustaka Pelajar.

Azwar, S. (2012). Reliabilitas dan Validitas. Pustaka Pelajar.

Bena, I. (2010). Evaluating Customer Satisfaction In Banking Services. Management \& Marketing, 5(2), 143-150.

Gunarsa. (2000). Psikologi Praktis, Anak Remaja dan Keluargae. PT. BPK Gunung Mulia.

Hastono, S. P. (2017). Analisis Data (2nd ed.). FKM UI.

Kemenkes. (2016). Peraturan Menteri Kesehatan RI (p. 41). Kemenkes RI.

Kuswandi, Sundjoto, Noor, A., \& Purwanto. (2015). Effects of Transformational Leadership, Personal values, Job Satisfaction on Lecturer Performance. Journal of Arts, Science \& Commerce, VI(April 2015), 84-93.

Lupiyoadi, Rambat, H. A. (2006). Manajemen Pemasaran Jasa. Salemba.

Polyorat, Kawpong; Sophonsiri, S. (2010). The Influence Of Service Quality Dimensions on Customer Satisfaction and Customer Loyalty in the Chain Restaurant Context: a Thai Case. Journal of Global Business and Technology; Huntington Station, 6(2), 64-76.

Saifuddin, \& Sunarsih. (2016). Pengaruh Kualitas Pelayanan terhadap Kepuasan Mahasiswa UIN Sunan Kalijaga Yogyakarta 1. 8(2), 177216.

Uddin, M. R., Mamun, A., Oumarou, A. S., \& Khan, M. M. (2017). Factors and Predictors of International Student's Satisfaction in Turkey. Educational Process: International Journal, 6(2), 43-52. https://doi.org/10.22521/edupij.2017.62.4 ISSN 2655-2434

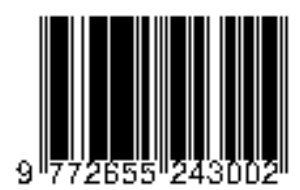

